\title{
PATTERN OF ATTENTIONAL TASK IMPAIRMENT IN SCHIZOPHRENIC PATIENTS: A STUDY REPORT
}

\author{
Singh Shailja ${ }^{1}$, Aich Kumar Tapas ${ }^{2}$, Ranjan Sanjeev², Kumar Abhinav ${ }^{3}$
}

\begin{abstract}
The present study attempted to find out the relationship between positive and negative clinical symptoms and various attentional task impairment in a group of schizophrenic patients.

METHODS: Fifty schizophrenic patients were assessed using the Positive and Negative Syndrome Scale (PANSS) by a trained psychiatrist (TKA) who was blind to attentional test measures and two groups, each of 25 positive symptom and 25 negative symptom schizophrenic patients, were formed. On these 50 patients with schizophrenia and 15 normal control groups, various attentional test measures were applied by a clinical psychologist (SS) who remained blind to the PANSS score.

RESULTS: It was found that schizophrenic patients were deficient in performing simple auditory and visual attentional tasks in comparison to normal subjects. The results of this study are inconsistent with the assumption that deficits in attention are uniquely associated with negative symptoms. The findings clearly support the hypothesis of a relationship between type of attentional processing and "dimensions" of schizophrenic symptomatology. The positive symptoms patients seem to be associated with attentional dysfunction especially selective attention and short term recall, whereas negative symptoms patients seem to be associated with different types of attentional deficits, e.g., sustained attention and visual attention.
\end{abstract}

CONCLUSIONS: The findings of our study are consistent with the existing literature that schizophrenic patients in general perform poorly on various measures of attentional tasks. Positive and negative symptoms schizophrenics have some correlation with distinct attentional deficits.

KEY WORDS: Schizophrenia; Positive Symptom; Negative Symptom;Attentional Task Impairment.

1. Senior Scientific Officer, Directorate General of Employment and Training. Ministry of Labour and Employment, Shahjahan Road, New Delhi 110001

2. Department of Psychiatry, Universal College of Medical Sciences \& Teaching Hospital, Bhairahawa, Nepal

3. BRD Medical College, Gorakhpur, Uttar Pradesh

\author{
For Correspondance: \\ Tapas Kumar Aich, DPM, MD \\ Professor, Department of Psychiatry, \\ Universal College of Medical Sciences \& Teaching Hospital \\ Bhairahawa, Nepal \\ e-mail:tapas_dr@rediffmail.com
}




\section{INTRODUCTION}

Attentional impairment has been noted in schizophrenic patients since the early description of the disorder. ${ }^{1,2}$ McGhie and Chapman in 1961 proposed that an attentional deficit constitute the core symptom of schizophrenia. ${ }^{3}$ Attentional impairments noted in schizophrenic patients include deficits in the ability in selectively attending to relevant information while ignoring unimportant information (selective attention), the ability to sustain concentration in continuous effort demanding situations (sustained attention) and reduction in the speed of perceptual and cognitive processing, including reduced reaction time.

Attentional deficits have been consistently found in schizophrenic patients; both during the overt psychotic states ${ }^{3,4}$ and while in remission ${ }^{5}$. Moreover attentional deficit is often considered as a 'marker' of vulnerability of schizophrenia because it also appears in children at high risk for the disorder $^{6,7}$ and in patients who are in remission ${ }^{5}$.

Early studies on attention in schizophrenia focused on reaction time. Studies by Huston and colleagues in 1937 revealed that schizophrenic patients reacted more slowly than normal subjects to simple stimuli. ${ }^{8}$ The attentional paradigm that has been studied most frequently in schizophrenia is the continuous performance test (CPT). Schizophrenics have been reported to be impaired relative to normal on variety of CPT Paradigms. ${ }^{9}$

But a review of literature on attention in schizophrenia reveals that attentional impairment may not be characteristic of all patients. Data available from different studies indicate that variables such as medication status, clinical state and the stage of illness can also influence the degree to which attentional distraction occur in patients with schizophrenia. ${ }^{10}$

The investigation of attentional performance in subgroups of schizophrenic patients is particularly relevant to the recently proposed sub-typing system differentiating positive from negative symptoms. ${ }^{11-14}$ So far, few studies have looked directly at the relationship between positive and negative symptom and attentional performance. Johnstone et al. administered a digit span task to schizophrenics and found that negative symptom patients showed deficits on the backward, but not the forward, condition. ${ }^{15}$

Cornblatt et al. in 1985 suggested that positive symptoms are associated specifically with distractibility; whereas negative symptoms were related only to more complex cognitive deficit. ${ }^{16}$ Similarly, Neuchterlein (1986) has reported that signal discrimination deficits on CPT and the FCSA were consistently related negative symptoms in subject with recent onset of schizophrenia. ${ }^{17}$ A number of significant correlations have been found between the SANS composite score and the pertaining attentional impairment item. Other researchers also found the positive correlation between negative symptoms score and attentional impairment. ${ }^{18,19}$ Roitman et al. (1997) indicated that neurocognitive markers of vulnerability to schizophrenia are associated with negative rather than positive symptoms. $^{20}$

However there are reports to the contrary. Allen in 1982 found no evidence of attentional impairment in negative symptom schizophrenics relative to other patients. ${ }^{21}$ Obiols et al. (1987) also assessed negative symptoms and neuropsychological performance in chronic schizophrenic patents, and reported that negative component was not linked with neuropsychological deterioration although negative symptomatology tended to be globally associated with cognitive impairment. ${ }^{22}$ Barbara Cornblatt and colleagues after assessing 59 schizophrenics reported that attention appeared to be independent of the clinical features of schizophrenia, attentional dysfunctions did not respond to neuroleptic medication, individuals with unusually early adolescent onset did not differ from schizophrenic patients with a more typical adult onset and no systematic clinical or cognitive differences were associated with length of illness. ${ }^{23}$ Though important research works have been reported from India in this field in the past we have very little literature on the pattern of attentional impairment in relation to the positive and negative symptom schizophrenia. The present study was conceptualized with this background knowledge.

We tried to investigate the relationship between the pattern of attentional task impairment and schizophrenic illness with a specific emphasis on the positive and negative dichotomy. The aim of the present study was (i) to compare the response pattern in schizophrenics vis-à-vis normal controls on certain attentional task measures, (ii) to evaluate the attentional dysfunction in different sub-types of schizophrenic illness (iii) to analyze the pattern of attentional dysfunction in the light of positive and negative syndrome schizophrenia and (iv) to examine the effect of the severity of illness on the attentional functioning of schizophrenics.

\section{METHODOLOGY}

The study was conducted at the Central Institute of Psychiatry, Kanke, Ranchi, in the state of Jharkhand, India. Study sample comprised fifty inpatient schizophrenics, diagnosed according to the ICD-10 and fulfilling our inclusion and the exclusion criteria. Inclusion Criteria were (I) Inpatient male schizophrenics in the age group of 18-45 years and having a 
minimum education up to $8^{\text {th }}$ standard. Exclusion criteria were evidence of organicity either from history or clinical examination, any comorbid major psychiatric disorder or mental retardation, any history of alcohol or drug dependence, being treated with ECT in the preceding 12 months, and patients who did not give consent to participate in the study. Fifteen age and education matched subjects who were unrelated to the patients and did not have any past history of substance abuse or mental illness, were taken up as control for the present study.

\section{PROCEDURE}

After taking the consent to participate in the study an unstructured interview was conducted to collect personal information about the subject with the help of relatives as well as the subjects. A specially designed socio-demographic and clinical data-sheet were prepared to note down patients age, level of education, occupation, age of onset of illness, total duration of illness, clinical diagnosis, etc.

A trained psychiatrist (TKA) rated these patients psychopathology using PANSS rating scale. The patients were placed in the "positive subtype", if they had a positive composite scale score valence and those with a negative valence were classified as "negative subtype". Fifty schizophrenics were thus separated into 25 positive symptom and 25 negative symptom schizophrenia cases. Various attentional tests were applied by the first author (SS), who was unaware about the positive and negative status of these patients. The psychological test batteries were applied within 48 hours of the administration of the PANSS.

Before starting the testing the subjects were informed about the purpose of the study and the importance of cooperation in the study. Subjects were tested in a private room. Following attentional tasks were given to both the patient as well as control groups: Digit span test, Vigilance task, Letter Cancellation Test, Digit Span with Distraction. Instruction, administration procedure and scoring were taken from the respective manuals. Item instructions were repeated or paraphrased as necessary to allow the client to understand.

Data thus obtained were subjected to following statistical analysis.

a) Descriptive Statistics: Mean, S.D. and percentage profile of different demographic and clinical variables.

b) One-way Analysis of Variance (ANOVA): One way ANOVA was preformed to compare performance among positive schizophrenic patients, negative schizophrenics and normal control subjects. c) Post-hoc analysis (Tukey-HSD Test): For multiple comparisons between groups post-hoc analysis with 'Tukeys Highly Significant Difference Test' (TukeyHSD) was performed. For carrying out detail statistical analysis computer assisted statistical programme (Statistical Package for Social Sciences SPSS Version 6.0 ) was used.

\section{DESCRIPTION OFTOOLS}

a) POSITIVE AND NEGATIVE SYNDROME SCALE $(\text { PANSS })^{24}$ :

The scale includes 30 items, 18 items from the Brief Psychiatric Rating Scale (BPRS) and 12 items from Psychopathology Rating Scale. Each item is accompanied by a complete definition as well as detailed anchoring criteria in a 7-point format rating from $1=$ absent to $7=$ extreme. The PANSS includes a 7-item scale for positive symptoms, a 7-item scale for negative symptoms and a 16 item scale covering general psychopathology.

The 7 positive items include delusions, conceptual disorganization, hallucinatory behaviour, excitement, grandiosity, suspiciousness, persecution and hostility. The 7 negative items are blunted affect, emotional withdrawal, poor rapport, positive/apathetic serial withdrawal, difficulty in abstract thinking, lack of spontaneity and flow of conversion and stereotype thinking.

The rating of the PANSS provide summary scores on the positive scale, negative scale, general psychopathology scale and a composite (positive minus negative) index. The PANSS scoring can be used for typological predominantly positive or negative syndrome.

b) ATTENTION \& CONCENTRATION:

This consists of Digit Forward (DF) test and Digit Backward (DB) test. Maximum score would be $8+8$.

c) VIGILANCETASK:

The auditory vigilance task was selected for the purpose consisted of alphabets from English. In this test the target letter "A" was randomly scattered with the frequency of 18 times out of 60 alphabets. Duration of the entire task was 90 seconds, in which letters were presented at the rate of one letter per second. Subjects were asked to tap once when he heard the target letter "A". For the uniformity of presentation tape recorded device was used. Two types of errors were noted: (i) Errors of omission or target misses, and (ii) Errors of commission or responses to non-targets. 
d) LETTER CANCELLATIONTASK:

The letter cancellation task, which is a vigilance task of visual modality, was selected for this purpose. It consists of alphabets from English, in which target letter "U" was randomly scattered with the frequency of times out of alphabets. There was no definite time limit for this lest. Subjects were asked to cancel "U" letter from the letter cancellation chart as early as possible. Two types of errors were noted: (i) Errors of omission or target misses, and (ii) Errors of commission or responses to non-targets. Total time taken to complete the task was also noted.

e) DIGIT SPAN TEST WITH DISTRACTION:

The digit span test with distraction was prepared by the investigator herself. For this purpose, forward series of digit span test of WAIS-R was taken, which consists of 3-6 digits arranged in difficulty order with alternate series. The original series were presented in female voice as target create distractibility the non-target digits from alternate series were presented in male voice at the same rate. But the non-target digits always come just after 0.5 seconds from the target digits. For the uniformity of presentation tape-recorded device was used.

In this task the patients were asked to repeat the digits, which were spoken in the female voice, after the examiner had said. The longest series repeated correctly was noted and it served as the score obtained.

\section{RESULTS}

Table: 1 Socio-demographic characteristic

\begin{tabular}{|l|c|c|l|l|c|}
\hline \multicolumn{1}{|c|}{ Variable } & $\begin{array}{c}\text { Positive } \\
\text { Schiz. } \\
(\mathrm{N}=25)\end{array}$ & $\begin{array}{c}\text { Negative } \\
\text { Schiz. } \\
(\mathrm{N}=25)\end{array}$ & $\begin{array}{c}\text { Normal } \\
\text { Control } \\
(\mathrm{N}=15)\end{array}$ & $F$ & $p$ \\
\hline $\begin{array}{l}\text { Age } \\
\text { (in years) }\end{array}$ & $\begin{array}{l}37.20 \\
(4.77)\end{array}$ & $\begin{array}{l}37.24 \\
(3.66)\end{array}$ & $\begin{array}{l}37.21 \\
3.97\end{array}$ & $\underline{0.005}$ & $\underline{\mathrm{NS}}$ \\
\hline $\begin{array}{l}\text { Education } \\
\text { (in years) }\end{array}$ & $\begin{array}{l}12.00 \\
(1.11)\end{array}$ & $\begin{array}{l}11.68 \\
(1.31)\end{array}$ & $\begin{array}{l}11.80 \\
1.29\end{array}$ & 0.422 & $\mathrm{~N} \mathrm{~S}$ \\
\hline $\begin{array}{l}\text { Age of onset } \\
\text { (in years) }\end{array}$ & $\begin{array}{l}22.20 \\
(4.77)\end{array}$ & $\begin{array}{l}22.24 \\
(3.66)\end{array}$ & - & 0.051 & $\mathrm{~N} \mathrm{~S}$ \\
\hline $\begin{array}{l}\text { Total duration } \\
\text { of illness } \\
\text { (in years) }\end{array}$ & $\begin{array}{l}11.80 \\
(1.58)\end{array}$ & $\begin{array}{l}12.01 \\
(1.28)\end{array}$ & - & 0.047 & $\mathrm{NS}$ \\
\hline
\end{tabular}

Table 1 showed that there was no significant difference between the two schizophrenic sub-types on various demographic and clinical variables. The table also showed that normal control group did not differ on age and education, in respect to schizophrenic population.
Table: 2 Clinical Scores

\begin{tabular}{|l|c|c|}
\hline Variable & $\begin{array}{c}\text { Positive } \\
\text { Schizophrenia } \\
(\mathrm{N}=25)\end{array}$ & $\begin{array}{c}\text { Negative } \\
\text { Schizophrenia } \\
(\mathrm{N}=25)\end{array}$ \\
\hline Positive & 35.60 & 12.60 \\
Symptoms & $(5.20)$ & $(2.94)$ \\
\hline Negative & 19.80 & 34.52 \\
Symptoms & $(6.97)$ & $(5.71)$ \\
\hline Composite & 16.12 & 21.92 \\
Index & $(4.57)$ & $(5.25)$ \\
\hline
\end{tabular}

Table 2 showed average positive and negative symptom scored and the composite index score by the positive and negative schizophrenic groups.

Table: 3 Comparison among positive schizophrenic, negative schizophrenics and normal control group on different attentional task measures:

\begin{tabular}{|l|l|l|l|l|l|}
\hline \multicolumn{1}{|c|}{ Variable } & $\begin{array}{c}\text { Positive } \\
\text { Schiz. } \\
(\mathrm{N}=25)\end{array}$ & $\begin{array}{c}\text { Negative } \\
\text { Schiz. } \\
(\mathrm{N}=25)\end{array}$ & $\begin{array}{c}\text { Normal } \\
\text { Control } \\
(\mathrm{N}=15)\end{array}$ & $\mathrm{F}$ & $\mathrm{p}$ \\
\hline $\begin{array}{l}\text { Digit Span Test } \\
\text { DF } \\
\text { DB }\end{array}$ & $4.20(0.43)$ & $4.56(0.50)$ & $7.12(0.43)$ & 292.0 & 0.00 \\
\hline Vigilance Task & $3.80(0.40)$ & $2.30(0.48)$ & $6.90(0.64)$ & 381.9 & 0.00 \\
EO & $5.96(0.67)$ & $5.60(1.19)$ & $0.20(0.90)$ & 251.25 & 0.00 \\
EC & $1.88(0.60)$ & $3.48(0.65)$ & $0.08(0.27)$ & 382.76 & 0.00 \\
\hline Letter Cancellation & & & & & \\
Task & $7.08(1.11)$ & $9.96(1.36)$ & $0.60(0.81)$ & 173.33 & 0.00 \\
EO & $1.68(0.69)$ & $3.16(0.68)$ & $0.08(0.27)$ & 455.59 & 0.00 \\
EC & $246.20(16.96)$ & $289.44(8.28)$ & $138.64(22.21)$ & 327.34 & 0.00 \\
RT (in sec) & & & & & \\
\hline Digit Span Test & $3.44(0.50)$ & $3.56(0.58)$ & $6.88(0.52)$ & 532.10 & 0.00 \\
With Distraction & & & & & \\
\hline
\end{tabular}

The mean profile configuration of the Digit Span test, Vigilance task, Letter Cancellation test, and Digit Span Test with Distraction for the positive and negative schizophrenics and the normal control group are presented in the table 3. One way ANOVA was carried out amongst these three groups to see the group difference for the each performance measures. 
Table 4: Post-Hoc. Multiple Comparison by Tukey HSD Test.

\begin{tabular}{|l|c|c|c|}
\hline Attentional Measures & $\begin{array}{l}\text { Positive Schiz. Vs. } \\
\text { Negative Schiz. }\end{array}$ & $\begin{array}{l}\text { Positive Schiz. Vs. } \\
\text { Control }\end{array}$ & $\begin{array}{l}\text { Negative Schiz. Vs. } \\
\text { Control }\end{array}$ \\
\hline $\begin{array}{l}\text { Digit Span Test } \\
\text { DF }\end{array}$ & NS & $*$ & $*$ \\
DB & $*$ & $*$ & $*$ \\
\hline Vigilance Task & & & $*$ \\
EO & NS & $*$ & $*$ \\
EC & $*$ & $*$ & $*$ \\
\hline Letter Cancellation Test & $*$ & $*$ & $*$ \\
EO & $*$ & $*$ & $*$ \\
EC & $*$ & $*$ & $*$ \\
RT (in sec.) & \multirow{2}{*}{ NS } & $*$ & $*$ \\
\hline Digit Span Test with & & & \\
Distraction & & & \\
\hline
\end{tabular}

*Significant at 0.05 level

NS: Not significant

Multiple comparisons were done between the 3 groups using Tukey-HSD test.

Results suggest that there was significant difference $(>0.05)$ between normal control group and positive schizophrenic, control and negative schizophrenics on the digit span test with or without distraction. But no statistical significance was found while correlating between positive and negative schizophrenics on these tests.

Statistically significant difference was found on vigilance task (on error of omission \& error of commission) between control and positive schizophrenics, control and negative schizophrenics as well as between positive and negative schizophrenics.

*Significant difference was also found on the letter cancellation test on the error of omission, error of commission and in response time, between control and positive schizophrenics, control and negative schizophrenics, as well as between positive and negative schizophrenics.

\section{DISCUSSION}

The findings of the present study indicate schizophrenic patients were deficient in performing simple auditory and visual attentional task in comparison to normal subject. Attentional deficits during active symptomatic phase of schizophrenic illness have been reported by several authors in the past. ${ }^{3,25}$ Walker and Harvey (1986) argued that attentional deficit among the schizophrenics may be a manifestation of disordered state of arousal, ${ }^{26}$ while Obiols et al. (1987) viewed attentional impairment as closest negative symptom to the component of defectual state. ${ }^{22}$

We found that performance of schizophrenics on digit span test, with or without distraction, compared to normal were poorer. A deficit in short term recall memory had been found in number of studies of schizophrenic patients. ${ }^{27,28}$ These studies have suggested that distraction exacerbate this deficit.

But despite the theoretical importance, the presumed association between negative symptom schizophrenia and attentional impairment remains largely untested. Andreasen found that items in the "attentional impairment" subscale of the scale for the assessment of negative symptoms correlated reasonably well $(0.19$ to 0.51$)$ with the other negative symptoms. ${ }^{11}$ This was taken as support for their inclusion as part of the negative symptom cluster.

The result of this study are inconsistent with the assumption that deficit in attention are uniquely associated with negative symptoms. In fact, negative symptom patients showed no significant performance deficit on the digit span test in both condition (with and without distraction). Instead the result suggested that positive symptoms were associated with impairment in selective attention. The positive schizophrenics performed worse than control group on both conditions of the digit span, and they showed a differential impairment in the distraction condition. Negative symptoms patients also showed some performance deficits relative to normal subjects. Various researchers in the past also found in their study that positive symptoms in schizophrenics were related to distractibility and display impaired selective attention in comparison to negative symptom schizophrenics. ${ }^{16,29}$

It is possible that the patients with negative symptoms are deficient in another type of attention. In the present study the negative symptom schizophrenics performed worse than positive symptom schizophrenics as well as from normal control group on digit span backward test (Table 3). Johnstone et al. also reported, in 1978, that the patients with negative symptom performed worse than other patients on a digital span backward test. $^{15}$

In our study, on vigilance task and letter cancellation task on error of omission there was no significant difference found between positive and negative symptom schizophrenics, but 
significant differences were found between normal control group and positive as well as negative symptom schizophrenics. However there was no significant difference found on error of omissions on vigilance task between positive and negative schizophrenics (Table 4). Negative symptom schizophrenics made more error of omissions and error of commissions on letter cancellation task in comparison to positive symptom schizophrenics. Visual attention as measured by continuous performance task (CPT) are proposed as the negative symptom linked vulnerability indicators by Addington and Addington in 1998. ${ }^{30}$ In Letter Cancellation Test, on response time, negative symptom schizophrenics had taken significantly more response time than positive symptom schizophrenics and normal control group (Table 4). Green and Walker in 1985 reported that schizophrenic patients with negative symptoms required a significantly longer inter stimulus interval to identify a target stimulus in a backward masking task. These results suggest that an early stage processing slow down may be associated with negative symptoms. ${ }^{29}$

The findings in our study clearly support the hypothesis of a relationship between type of attentional processing and "dimensions" of schizophrenic symptomatology. The positive symptoms seem to be associated with attentional dysfunction especially selective attention and short term recall. Consistent with previous reports of performance deficits in negativesymptom patients, ${ }^{15,29}$ the present findings suggest that there may be different types of attentional deficits, e.g., sustained attention and visual attention.

The findings are also consistent with previous reports indicating negative but not positive symptoms to be related to intellectual impairment. ${ }^{12,1531}$ Cornblatt et al. (2003) also reported that negative symptoms are associated with cognitive dysfunctions of more complex nature. ${ }^{32}$

\section{CONCLUSIONS}

The findings of our study are consistent with the existing literature that schizophrenics in general perform poorly on various attentional task measures. The results suggest the possibility of specific cognitive correlation of both positive and negative symptom dimension. Our study results confirmed the finding that selective attentional impairment is one of the characteristics of positive symptom schizophrenics and sustained impairment is characteristics of the negative symptom schizophrenics. These findings are at variance with those of Andreasen ${ }^{11}$ but are consistent with the results of few other workers ${ }^{29,33}$. These findings of our study, also, probably highlighted the fact that schizophrenic illness present universally with similar clinical characteristics across the racial or cultural boundaries.

\section{LIMITATIONS}

Only single gender, i.e., males was considered in the present study. Secondly, Demographic variables like socio-economic status; religion, caste etc. were not controlled, which might have influenced the results of the present study. Thirdly, the severity of psychopathology was not taken into consideration in this study. Fourthly, Neuroleptic doses received by the patients were not controlled in the present study. Finally, in this study letter cancellation test was used as a measure of sustained attention, whereas in similar other studies continuous performance test was used.

\section{REFERENCES}

1. Bleuler E. Dementia Praecox or the group of Schizophrenics. Translated by J. Zinkin Inc. International University Press: New York, 1950 .

2. Kraepelin E. Dementia praecox and paraphrenia (Translated by R. M Barclay). Living stone. Edinburgh, 1913.

3. McGhie A, Chapman J. Disorders of attention and perception in early schizophrenia. Br JMed Psychol, 1961: 34;103-116.

4. Asarnow RF, Sherman T. Studies of Visual Information Processing in Schizophrenic Children. Child Dev 1984: 55; 249-26l.

5. Wohlberg GW, Kometsky C. Sustained attention in remitted schizophrenics. Arch Gen Psychiatry 1973: 28;533-537.

6. Asarnow RF, Steffy RA, MacCrimmon DJ, Cleghorn JM. An attentional assessment of foster children at risk for schizophrenia. J Abnorm Psychol 1977: 86;267-275.

7. Asarnow RF, Granholm E, Sherman T. Span of apprehension in schizophrenia. In: Steinhauer SR, Gruzelier JH, and Zubin J, eds. Handbook of Schizophrenia: Neuropsychology, Psychophysiology, and Information Processing. Vol. 5. Amsterdam, The Netherlands. Elsevier Science Publishers, 1991: 335-370.

8. Huston PE, Shakow D, Riggs LA. Studies of motor function in schizophrenia:II. Reaction time. J Gen Psychol 1937: 16;39-82.

9. Walker E. Attention and neuromotor functions of schizophrenics, schizoaffective and patients with other affective disorders. Arch Gen Psychiatry 1981: 38; 1355-1358

10. Orzack MH, Kornetsky C. Attention dysfunction in chronic schizophrenia. Arch Gen Psychiatry 1966: 14,323-326.

11. Andreasen NC. Negative Symptoms in schizophrenia: Definition and reliability. Arch Gen Psychiatry 1982: 784-788

12. Andreasen NC, Olsen S. Negative versus Positive schizophrenia: Definition and validation. Arch Gen Psychiatry 1982: 39;789-794. 
13. Crow TJ. Positive and negative Schizophrenia symptoms and the role of dopamine. Br J Psychiatry 1980: 137383-386

14. Kay SR. Fiszbein A, Lindenmayer JP, Opler LA. Positive and Negative Syndromes in schizophrenia as a function of chronicity. Acta Psychiatr Scand 1986: 74(5);507-518.

15. Johnstone EC, Crow TJ, Frith CD, Stevens M, Keel L, Husband J. "The Dementia of Dementia Praecox". Acta Psychiatr Scand 1978: 57;305324.

16. Cornblatt BA, Lenzenweger MF, Dworkin RH, ErlenmeyerKimling L Positive and Negative schizophrenic symptoms, attention and information processing. Schizophr Bull 1985: 11(3);397-408.

17. Nuechterlein KH, Edell WS, Norris H, Dawson ME. Attentional vulnerability indicators, though disorders and negative symptoms. Schizophr Bull 1986: 12;408-426.

18. Goldberg TE, Kelsoe JR, Weinberger DR. Performances of schizophrenic patients on putative neuropsychological tests of frontal lobe function. Int JNeurosc 1990: 42;51-58.

19. Mortimer AM, Lund CE, McKenna PJ. The positive:negative dichotomy in Schizophrenia. BrJ Psychiatry 1990: 157;41-49.

20. Roitman SE, Keefe RS, Harvey PD, Siever LJ, Mohs RC. Attentional and eye tracking deficits correlate with negative symptoms in schizophrenia. Psychiatr Res 1997: 26;139-146.

21. Allen HA. Dichotic monitoring and focused versus divided attention in schizophrenia. Br JClin Psychol 1982: 21;205-212.

22. Obiols JE, Harcos T, Salanero M. Domenech JM. Negative symptoms and neuropsychological deficit in chronic schizophrenia. A factor analysis study. New Trends in Clin Experimental Psychol 1987: $3(4) ; 181-190$
23. Comblatt BA, Obuchowski M, Schnur DB, O'Brien JD. Attention and clinical symptoms in schizophrenia. Psychiatr Q 1997: 68;343-359.

24. Kay SR, Opler LA, Fiszbein A. The positive and negative syndrome scale (PANSS) for schizophrenia. Schizophr Bull 1987: 13;261-276.

25. Pogue-Geile MF and Oltmanns TF. Sentence perception and distractibility in schizophrenic, manic, and depressed patients. $J$ Abnorm Psychol 1980: 89;115-124.

26. Walker E, Harvey PD. Positive and negative symptoms in psychosis attentional performance correlates. Psychopathology 1986: 19;294-298

27. Koh SD, Kayton L, Berry R. Mnemonic organisation in young non psychotic schizophrenics. JAbnorm Psychol 1973: 81;299-310.

28. Chapmen LJ, Chapmen JP. Problems in the measurement of cognitive deficits Psychol Bull 1973: 79,380-385.

29. Green M, Walker E. Neuropsychological performance and positive and negative symptoms in schizophrenia. J Abnorm Psychol 1985: 94;460469

30. Addington $J$, Addington D. Visual attention and Symptom in Schizophrenia: A 1 year follow up: Schizophr Res 1998; 34(1-2);95-99.

31. Owens CDG, Johnstone EC. The disabilities of chronic schizophrenia their nature and the factors contributing to their development. $\mathrm{Br} J$ Psychiatry 1980: 136;384-395.

32. Cornblatt B, Lencz T, Smith CW, Correl CU, Auther AM, Nakayama E. The Schizophrenia Prodrome Revisited: A Neurodevelopmental Perspective. Schizophr Bull 2003: 29(4);633-651.

33. Bilder RM, Mukherjee S, Rieder RO, Pandurangi AK. Symptomatic and neuropsychological components of defect states. Schizophr Bull 1985: 11;409-419.

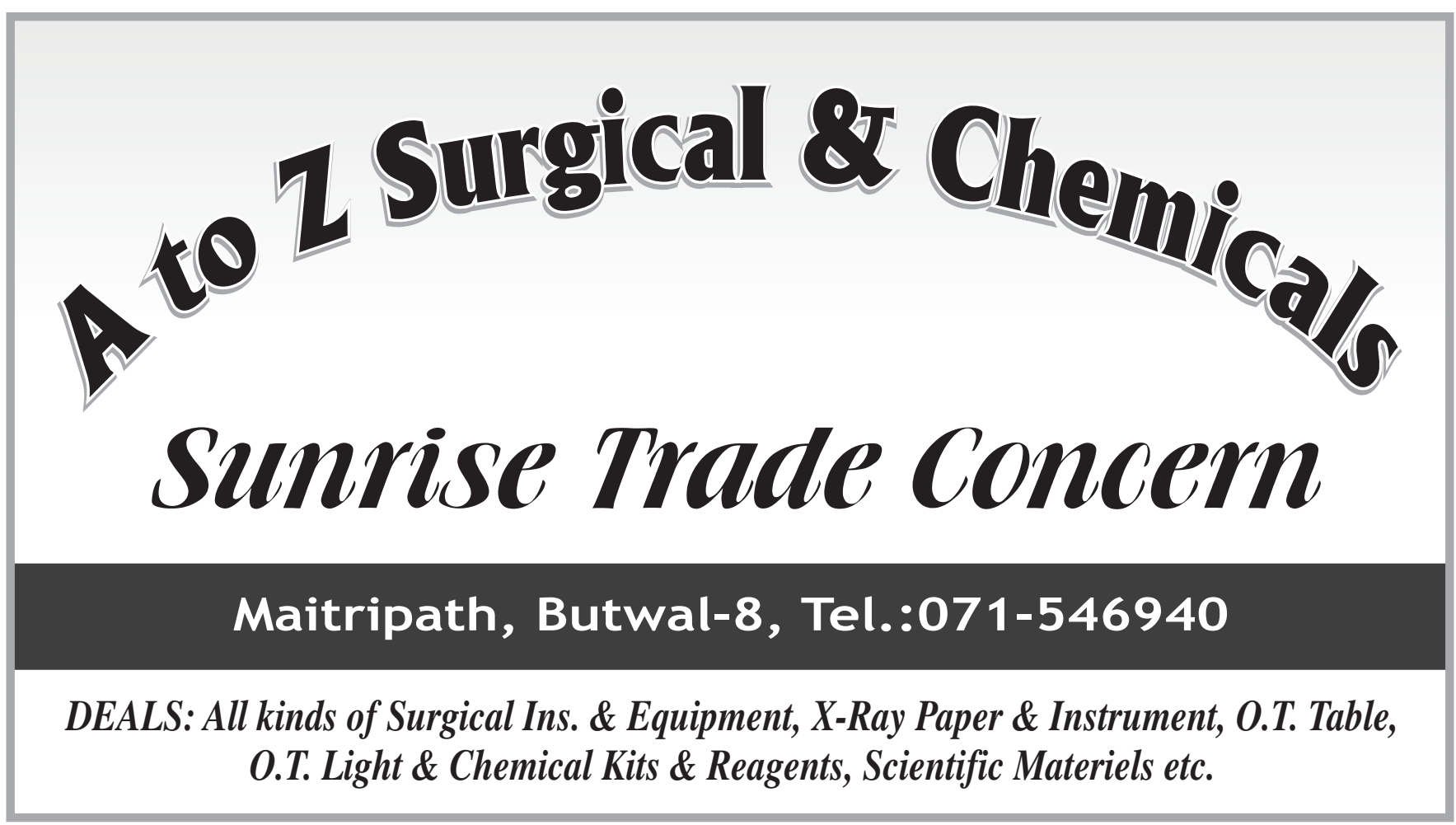

